\title{
Intrinsic Markers Reveal Breeding Origin and Geographically-Structured Migration Timing of Two Songbird Species at a Coastal Stopover Site
}

https://doi.org/10.1515/ami-2020-0005

Received December 13, 2019; accepted May 27, 2020

\begin{abstract}
We used stable hydrogen isotope markers to identify geographic provenance of Blackpoll Warblers (Setophaga striata) and Red-eyed Vireos (Vireo olivaceus) passing through a coastal stopover area in the Gulf of Maine on fall migration, and supplemented $82 \mathrm{H}$ signatures from feathers with wing length data as an additional proxy for migration origin, since geographic size variation has been documented for this species. We captured migrant blackpolls with putative origins from as close as the Adirondacks, New Brunswick, and northwestern Maine, and potentially as far as Alaska. We captured vireos with putative origins from as close as Maine and Nova Scotia, and potentially as far as British Columbia and Alberta. We found a significant relationship between blackpoll wing length and capture date indicating that birds with longer wings- and thus likely from more western and northern breeding regions - passed through the capture site earlier in the season than more local breeders. In contrast, vireos from more distant breeding latitudes passed through the capture site later in the season. These results demonstrate that mid-coast Maine serves as a catchment area for both Blackpoll Warblers, and Redeyed Vireos, and provides some evidence that connectivity between breeding areas and stopover sites may be strong for blackpolls; however, additional study linking breeding and stopover sites across the migratory range of both species is necessary to understand more fully how strong connectivity is between breeding and stopover areas for these species.
\end{abstract}

Keywords: blackpoll; isotope; migration; red-eyed vireo; wing length

\footnotetext{
*Corresponding author: David I. King, U.S. Forest Service Northern Research Station, University of Massachusetts Amherst, 201 Holdsworth Hall, Amherst, MA 01003, USA, E-mail: david.king2@usda.gov Jennifer R. Smetzer, Department of Environmental Conservation, University of Massachusetts Amherst, 204 Holdsworth Hall, Amherst, MA, 01003, USA
}

\section{Introduction}

Throughout their annual cycle, migrant songbirds move great distances, and occupy many distinct habitats and environmental conditions, complicating their conservation. Determining the geographic linkage between breeding areas, stopover sites, and wintering grounds for specific populations can aide in the conservation and management of migratory birds, and is an important research priority [1-3]. Data on migratory connectivity can help elucidate threats across multiple geographic scales, and thus can aid in identifying where populations are most limited [4-6]. Migratory connectivity also has important implications for the ability of breeding populations to respond to loss of non-breeding season habitats or other environmental change through phenotypic plasticity or genetic adaptations [7]. Though connectivity between breeding and wintering areas has been widely investigated [8-11] less is known about connectivity between breeding and stopover locations [12].

Understanding which breeding populations use regional stopover sites can be valuable for the monitoring, conservation, and management of migratory songbirds. For one, identifying links between breeding populations and specific stopover regions can greatly improve migration monitoring efforts by identifying sites that can effectively sample remote breeding populations that are not well represented in breeding-season surveys [13]. Information on the breeding origin of migrants is also critical for linking population trends from migration monitoring to specific breeding populations $[2,7,14$, $15]$, and for geographically targeting population-level conservation efforts for declining populations $[3,6,16]$. Determining links between breeding, wintering and stopover areas for specific breeding populations can also help determine geographically where mortality during the non-breeding period will most heavily affect breedingseason recruitment, and which breeding populations may be threatened by anthropogenic factors at different 
locations along the migratory route $[17,18]$. For instance, data on the geographic composition of migrants in regions of the Atlantic coastline facing significant urbanization or energy development can provide insight into which breeding populations may be adversely affected by stopover habitat loss or collision mortality.

Stable hydrogen isotope analysis has emerged as an important tool for investigating migratory connectivity and documenting the catchment areas of stopover sites [3]. The ratio of stable hydrogen isotope (deuterium; $82 \mathrm{H}$ ) in rainfall varies predictably across the North American continent in a latitudinal and altitudinal gradient because heavy isotopes are distilled from air masses as they move to cooler higher latitudes, or over orographic barriers [19]. Stable hydrogen isotopes in precipitation are transferred up trophic levels into growing feathers that become metabolically inert and subsequently retain a constant isotope signature reflecting the geographic origin of feather growth [20]. The $\delta 2 \mathrm{H}$ signature of feathers grown on the breeding grounds can thus be used to characterize the summer provenance of migratory songbirds. Stable hydrogen isotopes have been successfully used to identify the natal and breeding origin of many migratory bird species [14, 21]. The $\delta 2 \mathrm{H}$ signature of feathers has also been used to study geographic patterns in migration phenology, offering valuable insights into avian migration and ecology [15, 22-24].

One of the major limitations with using $\delta 2 \mathrm{H}$ to elucidate spatial and temporal patterns of migration is that individuals from the far western portions of North America have similar $82 \mathrm{H}$ signatures to those originating in the southern boreal forests of Canada. This reduces the assignment resolution for species with broad geographic breeding ranges, and limits the utility of using $\delta 2 \mathrm{H}$ signatures to investigate whether the timing of migration is geographically structured within a species. However, some morphological traits in songbirds, such as wing length or body size can also show predictable geographical variation $[25,26]$, and may therefore provide additional information regarding the temporal and spatial geographical structuring of migrants at stopover sites.

In this study we used stable hydrogen isotope markers to identify geographic provenance of Blackpoll Warblers (Setophaga striata: hereafter blackpolls) and Red-eyed Vireos (Vireo olivaceus: hereafter vireos) passing through a coastal stopover area in the Gulf of Maine on fall migration. These two species differ markedly in their migration strategy and movement patterns with blackpolls making longer stopovers, more landscape-scale stopover flights, and more frequent prolonged stopovers throughout the Gulf of Maine region $[27,28]$. Though both species exhibit over-water flights in the Gulf of Maine [28], blackpolls are uniquely known for their $2,500 \mathrm{~km}$ transatlantic flight from the eastern coast of the U.S. [29]. The Gulf of Maine hosts migrant songbirds from both the eastern Canadian provinces as well as boreal breeders as far west as Alaska $[30,31]$ making this an apt region for identifying catchment populations.

Our second objective was to assess whether there was geographic structure to the migration timing for these two species. We used continental-scale wing length data measured on breeding blackpolls and vireos as part of the Monitoring Avian Productivity and Survivorship (MAPS) program [32] to demonstrate that wing length varies predictably across latitude and longitude for both species. We expected blackpoll wing length could serve as proxy for migration distance because geographic size variation has been documented for this species [3335]; however, to the best of our knowledge, geographic patterns of vireo wing length have not been previously documented. We subsequently tested whether there was geographic structure to the timing of migration for the sampled blackpolls and vireos using $\delta 2 \mathrm{H}$ signatures and wing length data as indices of distance travelled to the capture site.

\section{Methods}

\subsection{Data collection}

Vireos and blackpolls were captured in the fall of 2013 and 2014 at the 888 ha Petit Manan Point section of the Maine Coastal Islands National Wildlife Refuge (Fig. 1) in Steuben Maine, United States $\left(44.40846^{\circ} \mathrm{N},-67.90502^{\circ} \mathrm{W}\right)$. We captured birds between September 6 and October 13 using passive mist-nets located in mixed forest and shrubland habitats. We outfitted all vireos and blackpolls with a USGS aluminum band, and recorded age, un-flattened wing chord and collected feather samples. We only sampled feathers from hatch year vireos, as they constitute $~ 98 \%$ of the demographic in coastal areas, but sampled from both hatch year and after hatch year blackpolls. Both focal species undergo a first prebasic molt on the breeding grounds that includes the body feathers [33], so feathers accurately reflect the natal/breeding origin. We sampled the third retrix on the right for vireos, as this is less prone to loss and subsequent regrowth than outer rectrices. We sampled upper back feathers between the scapulars from blackpoll warblers, to avoid interference with flight capability [30]. 


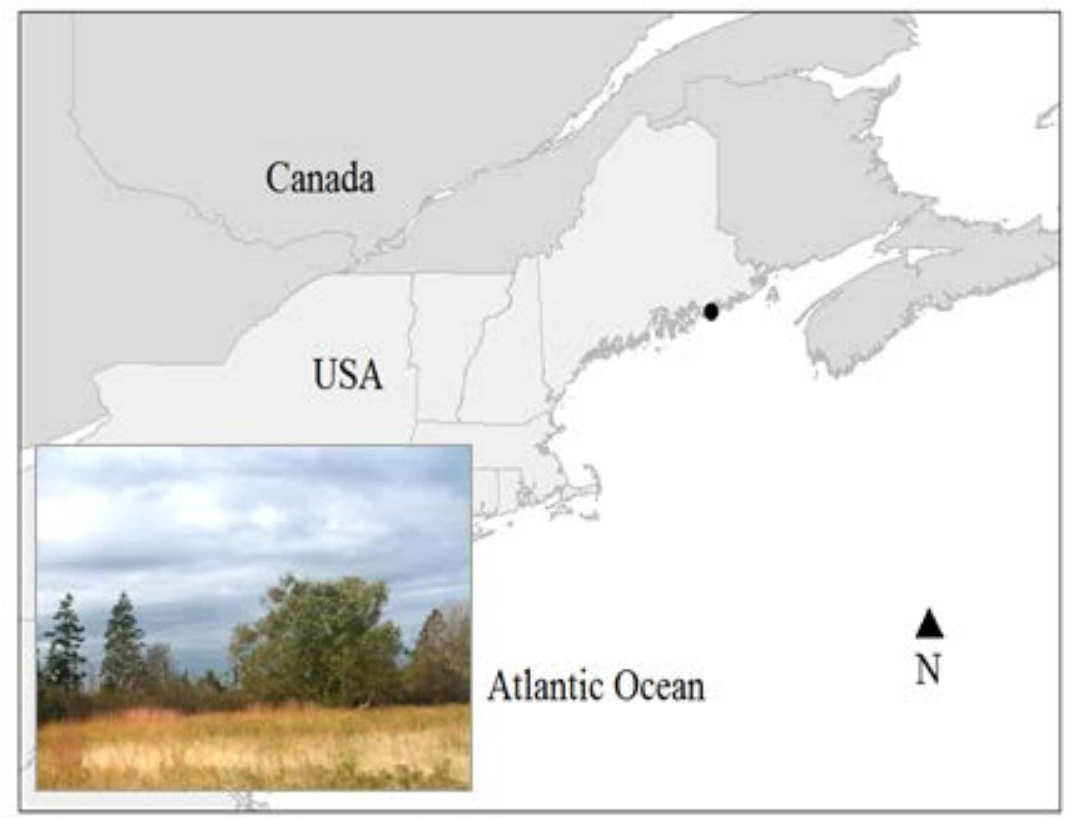

Figure 1. Location of the Petit Manan Point study site where migrants were captured in the fall of 2013 and 2014, with a photograph of the field site inset.

\subsection{Stable isotope analysis}

Feathers were prepared and analyzed for $\delta^{2} \mathrm{H}$ at the Cornell University Stable Isotope Laboratory (COIL), Ithaca New York. Feathers were held at the lab for a week before preparation, washed in 2:1 chloroform: methanol solution overnight, and dried for several days in a fume hood. Subsamples were cut from the distal vane, and weighed $(0.35 \pm 0.02 \mathrm{mg})$ into silver capsules without grinding. The samples were analyzed for stable hydrogen isotope content on a Thermo Delta $\mathrm{V}$ isotope ratio mass spectrometer (IRMS) interfaced to a Temperature Conversion Elemental Analyzer (TC/EA). The samples were analyzed under the comparative equilibrium method of [36] with three calibrated keratin $\delta^{2} \mathrm{H}$ references run every 10 samples: CBS, KHS and an internal COIL keratin standard. Isotope corrections were performed using two established CBS and KHS standards of $[30,36]$. Across all the sample runs the standard deviation for the internal keratin, $\mathrm{CBC}$ and KHS standard was $2.6 \%$, $2.1 \%$ ond $2.4 \%$ respectively in 2013 and 3.3\%, 2.7\%o and 2.6\% respectively in 2014. We reported all results for nonexchangeable $\delta^{2} \mathrm{H}$ in delta notation of units per mil (\%o), normalized to the Vienna Standard Mean Ocean Water (VSMOW) standard scale, where $\delta=\left(R_{\text {sample }}-R_{\text {standard }}\right) / R_{\text {standard }}$, and $R$ is the abundance ratio of the heavy and light hydrogen isotopes [37].

\subsection{Assignment of molt origins}

We estimated geographic origins based on spatiallyexplicit likelihood-based assignment methods [3, 38], and a GIS model of expected $\delta^{2} \mathrm{H}$ in precipitation $\left(\delta^{2} \mathrm{H}_{\mathrm{p}}\right)$ over the growing season [19]. We converted this GIS model to a digital map of expected $\delta^{2} \mathrm{H}$ feather values $\left(\delta^{2} \mathrm{H}_{\mathrm{f}}\right)$ using the rescaling equation presented in [38] for non-ground foraging Neotropical migrants:

$$
\delta^{2} H_{f}=-17.75+0.95 * \delta^{2} H_{p}
$$

derived by relating $\delta^{2} \mathrm{H}_{\mathrm{f}}$ to $\delta^{2} \mathrm{H}_{\mathrm{p}}$ for a calibration set of birds with known breeding origins. We used digital range maps to restrict the resulting feather isoscape to each species' respective breeding range, and thus limit the geographic range of assignments. Previous studies using likelihood-based density models to perform assignment have incorporated abundance data from the Breeding Bird Atlas Surveys (BBS) as Bayesian priors to improve estimates. However, we did not use Bayesian priors as these species can breed north of the region covered by BBS routes [3]. We calculated the probability that each cell in the feather isoscape represented the origin for each bird using a normal probability density function: 


$$
f\left(y^{\prime} \mid \mu_{c}, \sigma_{c}\right)=\left(\frac{1}{\sqrt{2 \pi \sigma_{c}}}\right) \exp \left[-\frac{1}{2 \pi \sigma_{c}^{2}}\left(y^{\prime}-\mu_{c}\right)^{2}\right]
$$

...where $y$ ' is the unknown origin of an individual bird, $\mu_{\mathrm{c}}$ is the expected $\delta^{2} \mathrm{H}_{\mathrm{f}}$ value of a given cell $c$, and $\sigma_{\mathrm{c}}$ is the expected standard deviation of $\delta^{2} \mathrm{H}_{\mathrm{f}}$ for birds growing their feathers at the same location. We used the value of $14.4 \%$ reported in [38] for non-ground foraging Neotropical migrants in North America; the value was derived from the residuals of their best model relating $\delta^{2} \mathrm{H}_{\mathrm{f}}$ to $\delta^{2} \mathrm{H}_{\mathrm{p}}$ for birds with known origins.

We used Eq. 2 to generate a spatially-explicit map for each individual bird that represented the probability of origin in each cell of the feather isoscape based on expected and observed $\delta^{2} \mathrm{H}_{\mathrm{f}}$ values. For each individual bird, we standardized each cell value in the isoscape by the total probability summed over all cells; we subsequently assigned each cell a value of 1 if the probability value in the cell was $\geq$ the $67 \%$ quantile of probability of origin values for that individual and a 0 if it was not [3]. This effectively assigned a cell as a possible origin based on a 2:1 odds ratio of being correct, and allowed multiple possible origins per individual [3]. The 2:1 odds ratio was chosen because previous studies demonstrated that this level of certainty resulted in classification rates that were better than that expected by chance alone [39]. We summed the cell values for all individuals by species to generate a probability surface representing likely origins of individuals within our sample [40]. We conducted this analysis in the R statistical environment [41] using the maps[42], maptools [43], and raster [44] packages.

\subsection{Continental Patterns in Wing Length}

We used un-flattened wing chord data collected across North America during the breeding season from 1989 to 2015 by the Monitoring Avian Productivity and Survivorship (MAPS) program [32] to test if wing length varied predictably across the continent for blackpolls and vireos. For each species, we excluded birds with an un-flattened wing chord measurement $\geq 3$ SD from the mean to account for errors, and included only birds measured in June and July. We only included data from banding stations located $>44^{\circ} \mathrm{N}$ to limit our analysis to plausible breeding latitudes for our capture site, and excluded stations with $<5$ wing measurements for a species. This resulted in a data set of 2480 vireos measured at 97 MAPS stations, and 556 blackpolls measured across 29 MAPS stations (Fig 2). Following [26], we related mean un-flattened wing chord at each station latitude and longitude by species using general linear models.
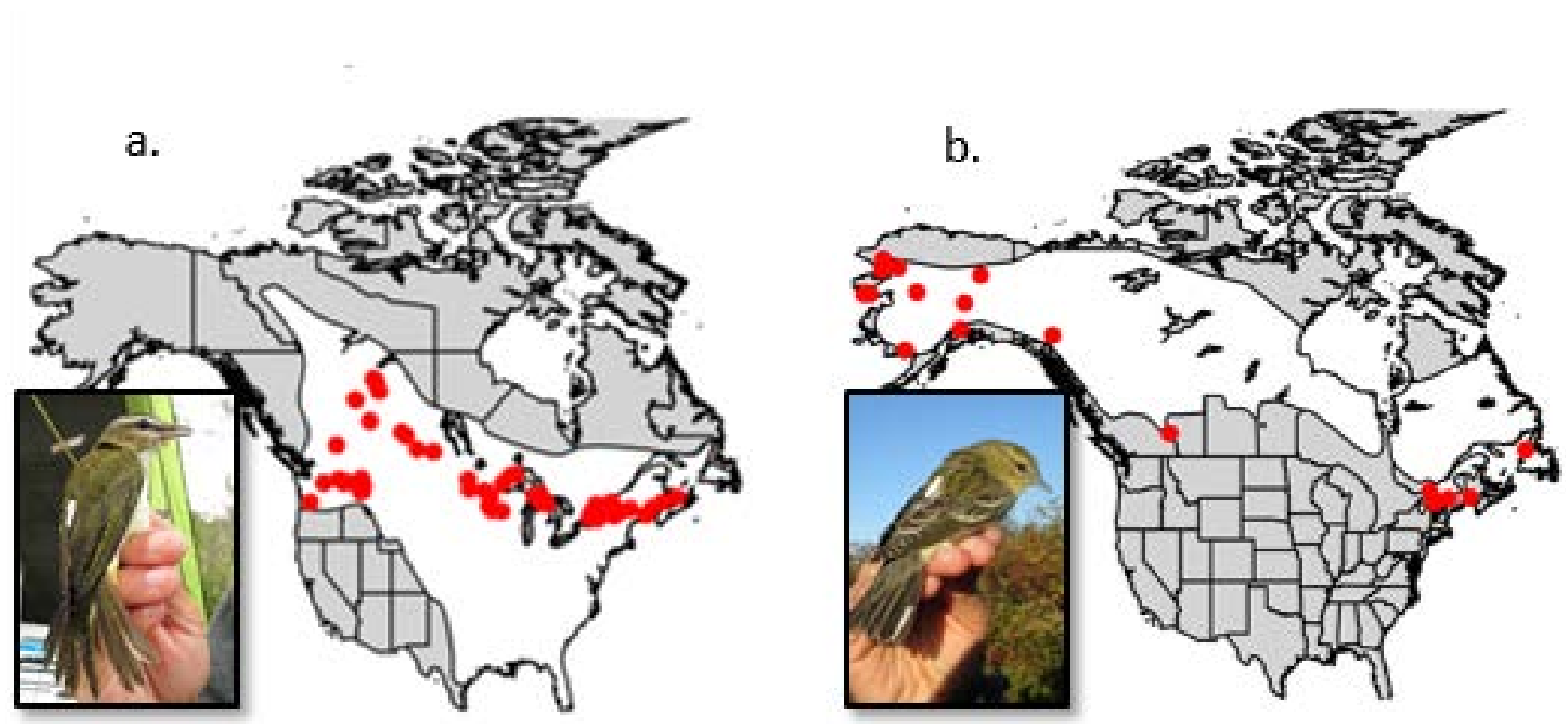

Figure 2. Monitoring Avian Productivity and Survivorship (MAPS) stations used to compare a. Red-eyed Vireo (Vireo olivaceous) and b. Blackpoll Warbler (Setophaga striata) wing lengths across latitude and longitude. The breeding range of each species is shown in white, and photos (c) Jared Feura of both species are shown with their corresponding maps. 


\subsection{Migration Timing}

We fit linear regression models relating $\delta^{2} \mathrm{H}$ to capture date to test whether the timing of migration was geographically structured. We analyzed the two species separately because we expected they could exhibit different patterns. For each species, we scaled capture date and $\delta^{2} \mathrm{H}$ values by their mean to account for any inter-annual differences in these values before pooling the two years of data. Although age-related differences in $\delta^{2} \mathrm{H}$ enrichment have been found in previous studies $[30,45,46]$, we found no differences in $\delta^{2} \mathrm{H}$ enrichment between ages for blackpolls $(\mathrm{t}=-0.65, \mathrm{p}=0.051)$, so we pooled the data for adult and hatch year birds. We used general linear models to test the hypotheses that 1) $\delta^{2} \mathrm{H}$ values were related to capture date, and 2) wing length was related to capture date. We considered covariates as highly significant predictors if $95 \%$ confidence intervals for the parameter estimate excluded zero, and as moderately significant predictors if $90 \%$ confidence intervals excluded zero.

\section{Results}

We collected feathers from 23 blackpoll warblers and 58 vireos in 2013, and 70 blackpolls and 82 vireos in 2014. Both the blackpolls and vireos we sampled at the capture site covered a broad isotopic range with blackpoll $\delta^{2} \mathrm{H}$ values ranging from $-73.8 \%$ o to $-177.7 \%$, and vireo $\delta^{2} \mathrm{H}$ values from $-56.2 \%$ o to $-119.9 \%$ (Table 1 ). We captured migrant blackpolls with putative origins from as close as the Adirondacks, New Brunswick, and northwestern Maine, and potentially as far as Alaska. We captured vireos with putative origins from as close as Maine and Nova Scotia, and potentially as far as British Columbia and Alberta. Sixty nine percent of our blackpoll sample had $\delta^{2} \mathrm{H}$ values consistent with origins north and west of Manitoba (i.e., $\delta^{2} \mathrm{H}<-120 \%$; Fig. 3), and $71 \%$ of our vireo sample had $\delta^{2} \mathrm{Hf}$ values consistent with origins well north and west of Lake Superior (i.e., $\delta^{2} \mathrm{H}<-85 \% 0$ ). Most blackpolls were assigned to northwestern British Columbia, northern Alberta, the southern reaches of the Northwest Territories, and eastern Alaska, while most vireos were assigned to the central portion of their breeding range, Washington, or southern British Columbia (Fig 3). Although we have visualized the isotope ranges throughout the entire vireo breeding range, it is unlikely that we captured migrants from areas far south of our study site; these regions simply have similar rainfall isotope patterns to other vireo breeding areas to the north of the study site [19].
Vireos measured at MAPS stations from more eastern longitudes (general linear model; $\beta=0.01 ; P=0.03$ ), and southern latitudes (general linear model; $\beta=-0.06 ; P=$ 0.002) had significantly longer wings than birds from more western longitudes and northern latitudes (Fig 4). Despite this continental-scale variation in wing length, we did not find a significant relationship between wing length and $\delta^{2} \mathrm{H}$ values for our sample of migratory vireos (general linear model; $\beta=0.02 ; P=0.37$ ). Blackpoll wing length varied significantly across the continent, but
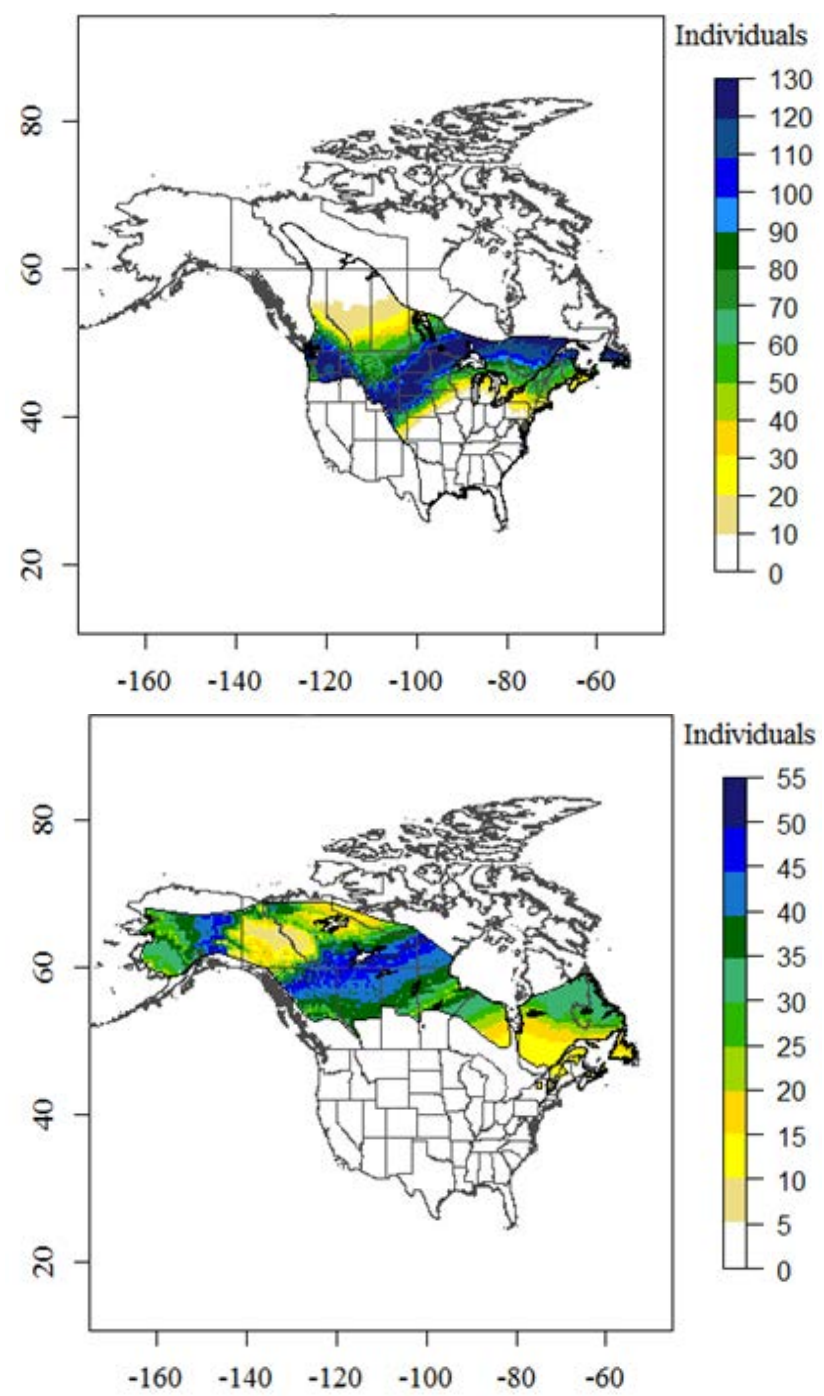

Figure 3. Likelihood-based assignment of putative breeding/natal origin for red-eyed vireos (left) and blackpoll warblers (right) captured during fall migration at Petit Manan Point in Steuben Maine in 2013 and 2104, based on stable hydrogen isotope analysis of migrant feathers. The scale on the legend indicates the number of individuals that were consistent with the isotope value in a given cell of the isotope map, under 2:1 odds of correct assignment. The breeding range of each species is outlined in black. 
showed the opposite pattern to that of vireos. Blackpolls measured at MAPS stations from more western longitudes (general linear model; $\beta=-0.03 ; P<0.001$ ), and northern latitudes (general linear model; $\beta=0.10 ; P=0.001$ ) had longer wings than birds from more eastern longitudes and southern latitudes (Fig 4). The blackpolls we sampled in Maine reflected this pattern; birds with more negative $\delta^{2}$ $\mathrm{H}$ values (i.e. from more western breeding latitudes) had significantly longer wings than birds with larger $\delta^{2} \mathrm{H}$ values (general linear model; $\beta=-2.2 ; P=0.02$ ).

Blackpoll capture date and $\delta^{2} \mathrm{H}$ values were not significantly related (general linear model; $\beta=-0.06 ; p$ $=0.87$ ). However, we found a significant relationship between blackpoll wing length and capture date indicating that birds with longer wings- and thus likely from more western and northern breeding regions passed through the capture site earlier in the season than more local breeders (general linear model; $\beta=-2.2$;
$P=0.02)$. In contrast, we found moderate evidence of a significant relationship between capture date and $\delta^{2} \mathrm{H}$ for vireos (general linear model; $\beta=-0.19 ; p=0.07$ ) indicating that vireos from more distant breeding latitudes passed through the capture site later in the season. Vireo wing length and capture date were not however significantly related (general linear model; $\beta=-0.02 ; p=0.51$ ).

\section{Discussion}

Despite the coarse precision of the likelihood assignment, our results demonstrate that the Gulf of Maine is a catchment area for eastern and western populations of both Blackpoll Warblers and Red-eyed Vireos during fall migration. Roughly $95 \%$ of the vireos we captured $(\mathrm{N}=$ 133) had an $\delta^{2} \mathrm{H}$ signature that indicated a putative origin west or north of the capture location (i.e. > $-75 \delta^{2} \mathrm{H} \%$ ),
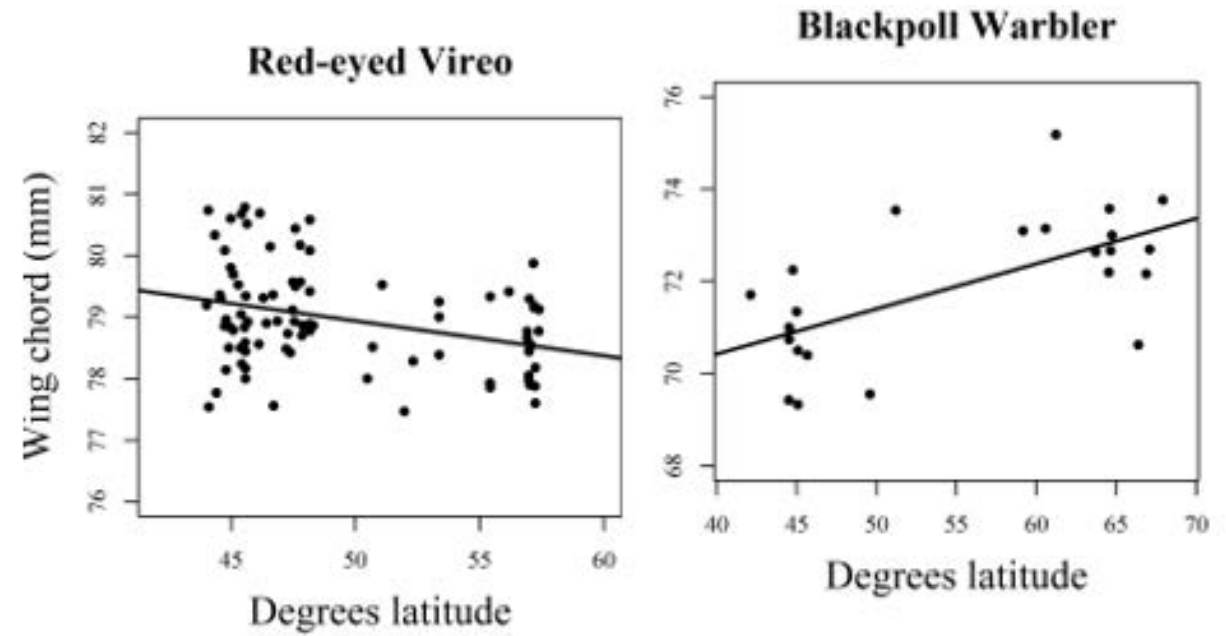

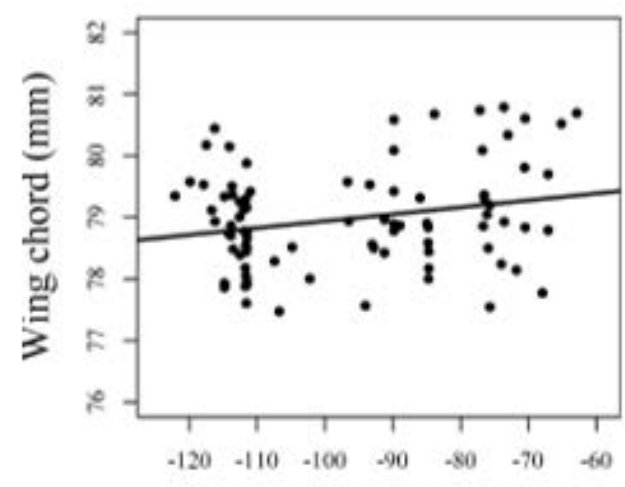

Degrees longitude

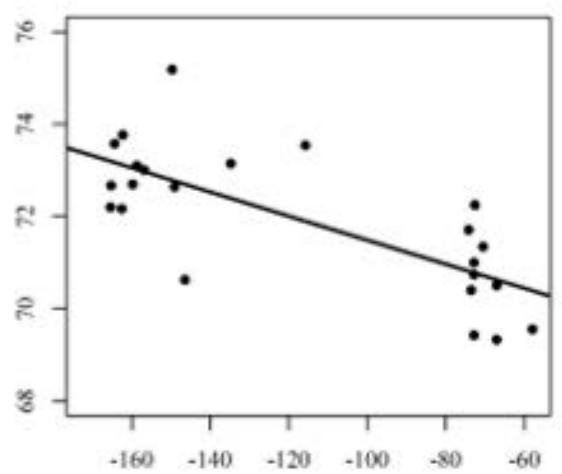

Degrees longitude

Figure 4. Relationship between Blackpoll Warbler (Setophaga striata) and Red-eyed Vireo (Vireo olivaceous) wing lengths across latitude and longitude. 
suggesting that migration monitoring in the Gulf of Maine can sample vireos from a broad continental range, not just local breeders. Furthermore, at least 120 individuals from our sample were assigned origins in the northern reaches of Newfoundland and central Quebec where BBS routes are not well represented. Thus, the Gulf of Maine, and nearby coastal stations could serve as an important migration monitoring area for these more remote Redeyed Vireo breeding populations.

Reflecting this, Manomet Bird Observatory on the east coast of Massachusetts observed a significant $40 \%$ decline in fall and spring capture rates of Red-eyed Vireos from the 1970-1985 and 1986-2001 migration monitoring periods despite increases or non-significant decreases across the local physiographic strata [47], and an overall range-wide increases of $0.75 \%$ for the species between 1966 and 2015 across BBS routes [48]. Our results suggest that it is possible that Manomet trends could reflect declines at northern breeding areas poorly represented by BBS routes; indeed, despite general overall population increases, western breeding populations of Red-eyed Vireos decreased by 2\% annually from 1980-1994, with particularly large declines of $2.4 \%$ in British Columbia and $2.6 \%$ in the central Rockies from 1966- 1994 [49]. Thus, characterizing $\delta^{2} \mathrm{H}$ signatures for Red-eyed Vireos at a range of coastal sites in the Northeastern US with well-established migration monitoring programs may be valuable for understanding trends for this species, particularly given the low recapture rates between breeding and migration for vireos $(<0.003 \%$; USGS unpublished data).

Although it is well known that blackpolls have a significant eastern component to their fall migratory movements, there is limited information on where different populations reach the Atlantic shoreline [50]. Migration monitoring north and east of our study site, at the Atlantic Bird Observatory (ABO) in southern Nova Scotia found that blackpolls were predominantly from breeding grounds east of Hudson Bay and the Great Lakes [15]. Our results demonstrate that mid-coast Maine is a catchment area for blackpolls from across their breeding range, including birds from eastern breeding grounds (as sampled at the ABO), as well as birds from the central and northwest portion of the breeding range and eastern Alaska that likely reach the coast slightly south and west of the eastern breeders. Our findings are congruent with [30] who sampled blackpolls at a site $\sim 100 \mathrm{~km}$ southwest of our study site during 2009-2011. Another study [46] found that blackpolls captured west of the Gulf of Maine, in the Great Lakes region and Pennsylvania were from Canadian breeding sites further northwest than those primarily represented in our sample, and that individuals collected southwest of our study site in Boston and Manomet Bird Observatory were primarily from Canadian breeding ranges to the southwest or our study site, but further west in Alaska. Collectively these results suggest that there may be a northeast to southwest gradient in where various breeding populations reach the Gulf of Maine, with northeastern reaches of the Gulf of Maine seeing more eastern breeders, and more southwestern areas seeing more western breeders. Such a pattern would suggest reasonably strong connectivity between breeding populations and stopover regions for blackpolls; however replicated sampling at more geographic areas would be necessary to test these patterns more fully.

Our findings have a number of important conservation implications. First, our work suggests the Gulf of Maine can serve as an excellent location for blackpoll migration monitoring, since much of this species' boreal breeding range is poorly represented in BBS routes [15]. Our results also indicate that habitat loss and energy development in this region could pose threats to blackpoll breeding populations that are already facing the most dramatic declines. Although blackpoll warblers have exhibited one of the highest sustained rates of population decline of any Neotropical migrant in the last few decades [48, 51], trends appear to be highly variable across breeding populations. In specific, the western boreal and Alaskan populations of blackpolls that are most commonly represented in our sample are facing the most severe declines with 71 and 95\% regional population declines respectively from 1970 to 2014 [51]. The breeding regions strongly represented in our blackpoll migrant sample from the Gulf of Maine have experienced some of the greatest rates of forest decline in North America in the last decade or so [52]. In turn, these losses may be responsible for the $70 \%$ decline in blackpolls numbers observed during fall migration at Manoment Bird Observatory on the Massachusetts coast since the 1970s [47]. Given that this region serves as an important staging resource for blackpolls to refuel before epic transoceanic migratory flights [27, 29] conservation of these regional stopover resources is likely an important priority for blackpolls.

Using a combination of intrinsic markers, we successfully identified geographic structure to the timing of migration for both species, despite overlap in the $\delta 2 \mathrm{H}$ signatures for blackpolls originating from southern boreal forests and western portions of North America. The results of our stable isotope regression coincide with numerous previous studies that found no significant relationship between $\delta 2 \mathrm{H}$ signatures and capture date for blackpolls $[15,30,46,53]$. However, by validating that blackpoll wing length varied geographically across North America, and 
using this morphological feature as an additional index for distance to breeding locale, we provide indirect evidence that blackpolls from more distant breeding areas reached the Gulf of Maine before their more southern and eastern conspecifics. This migration pattern could be a result of the earlier changes in temperature and food resources at northern latitudes, such that a strategy of leaving earlier, in anticipation of impending snow is more important and particularly adaptive for individuals breeding at higher latitudes [54]. Indeed, seasonal declines in ecological productivity across North America are strong predictors of migratory departure, particularly for omnivorous or insectivorous species [55]. In further support of this hypothesis, similar migratory patterns have been seen for Yellow Warblers (S. petechia) and Wilson's Warblers (Cardellina pusilla), both of which also have breeding ranges that extend to the far northern and northwestern limits of North America [22, 24].

Vireos exhibited the opposite pattern of blackpolls with individuals from northern latitudes passing through the study site later in the fall migration period than more southern conspecifics. This pattern has also been observed for Yellow-rumped Warbler, Northern Waterthrush [15], Orange-crowned Warblers (Vermivora celata), and Common Yellowthroats (Geothlypis trichas) [22]. It is possible that we observed this geographic structure to migration simply because breeders from more southern latitudes reached the coast sooner than conspecifics that had further to travel. One hypothesis that is commonly offered for southern breeders migrating earlier than northern breeders is that southern populations forgo the opportunity for double brooding in favor of the benefits that may be gained from earlier arrival on the breeding grounds [54]. Though our sample was entirely hatch year birds, if adults in northern latitudes tended to double brood more frequently than more southern conspecifics, the breeding season, and thus the departure of juveniles could be delayed in more northwestern breeding regions.

It is also possible that Red-eyed Vireos exhibit Type I leapfrog migration, in which southern breeding populations migrate earlier than northern conspecifics, and occupy the more northern portions of the species wintering range [56]. In Type I leapfrog migration, it is often the larger individuals that occupy the more southern breeding areas, and the more northern wintering latitudes, and smaller individuals that tend to inhabit northern breeding latitudes and more southern wintering areas, possibly as an evolutionary repercussion of smaller individuals being forced out of the closer (i.e. more northern) wintering sites through competition [57]. In support of this hypothesis, we found that vireos from southern latitudes and eastern longitudes had longer wings, and migrated earlier than their northern/western conspecifics. Further study of where different breeding populations of Red-eyed Vireos winter could help test whether vireos do in fact exhibit this Type I leapfrog pattern, like other species with similar geographic variation in body size.

\section{Conclusion}

Migration monitoring indicates that many songbirds are exhibiting significant long-term declines [15, 47]. Effectively conserving these species requires a full life cycle understanding of what factors are limiting populations, and information about where specific breeding populations face anthropogenic threats throughout the annual cycle [17]. Although migration is a time of exceptional energy demand and mortality for songbirds, more research on connectivity has focused on breeding and winter ground connectivity than migratory stopover sites. Our work demonstrates that mid-coast Maine serves as a catchment area for both Blackpoll Warblers, and Redeyed Vireos, and provides some evidence that connectivity between breeding areas and stopover sites may be strong for blackpolls; however, additional study linking breeding and stopover sites across the migratory range of both species is necessary to understand more fully how strong connectivity is between breeding and stopover areas for these species. Further study linking stopover sites to wintering locations will also ultimately be needed to fully model threats across the annual cycle for these species.

Acknowledgements: We thank A. Leppold, J. Reese, J. Feura, T. Duclos, J. Ruebesam, M. Akresh, and B. Bailey for help in the field, and P. Taylor, B. Woodworth, J. Brzustowski, N. Pau, K. O’Brien, L. Welch, S.Williams, J. Fortier, C. Familiaris, and the College of the Atlantic for logistical support. This study was funded by the U.S. Fish and Wildlife Service, the USDA Forest Service, and the National Science Foundation-sponsored IGERT: Offshore Wind Energy, Engineering, Environmental Science, and Policy (grant no. 1068864). This work was executed in accordance with proper Institutional Animal Care and Use (IACUC) protocols and permits, including University of Massachusetts IACUC protocol no. 2013-0019 and U.S. Federal Bird Banding Permit no. 23140. 


\section{References}

[1] Faaborg J., Holmes R.T., Anders A.D., Bildstein K.L., Dugger K.M., Gauthreaux S.A., et al., Conserving migratory landbirds in the New World: do we know enough?, Ecol. Appl., 2010, 20, 398-418

[2] Webster M.S., Marra P.P., Haig S.M., Bensch S., Holmes R.T., Links between worlds: unraveling migratory connectivity, Trends Ecol. Evol., 2002, 17, 76-83

[3] Hobson K.A., Van Wilgenburg S.L., Faaborg J., Toms J.D., Rengifo C., Sosa A.L., et al., Connecting breeding and wintering grounds of Neotropical migrant songbirds using stable hydrogen isotopes: a call for an isotopic atlas of migratory connectivity, J. Field Ornithol., 2014, 85, 237-257

[4] Myers J.P., Morrison R.I.G., Antas P.Z., Harrington B.A., Lovejoy T.E., Sallaberry M., et al., Conservation strategy for migratory species, Am. Sci., 1987, 75, 18-26

[5] Moore F.R., Gauthreaux S.A., Kerlinger P., Simons T.R. Habitat requirements during migration: Important link in conservation, In: Martin T.E., Finch D.M. (Eds.), Ecology and management of Neotropical migratory birds, a synthesis and review of critical questions, Oxford, Oxford University Press, 1995, 121-144

[6] Sherry T.W., Holmes R.T. Summer versus winter limitation of populations: what are the issues and what is the evidence?, In: Martin T.E., Finch D.M. (Eds.), Ecology and management of neotropical migratory birds, a synthesis and review of critical questions, Oxford, Oxford University Press, 1995, 85-120

[7] Webster M.S., Marra P.P. The importance of understanding migratory connectivity and seasonal interactions, In: Greenberg R., Marra P.P. (Eds.), Birds of Two Worlds: The Ecology and Evolution of Temperate-Tropical Migration, Baltimore Maryland, The Johns Hopkins University Press, 2005, 199-209

[8] Chamberlain C.P., Blum J.D., Holmes R.T., Feng X., Sherry T.W., Graves G.R., The use of isotope tracers for identifying populations of migratory birds, Oecologia, 1997, 109, 132-141

[9] Hobson K.A., Wassenaar L.I., Linking breeding and wintering grounds of Neotropical migrant songbirds using stable hydrogen isotopic analysis of feathers, Oecologia, 1997, 109, 142-148

[10] Kelly J.F., Ruegg K.C., Smith T.B., Combining isotopic and genetic markers to identify breeding origins of migrant birds, Ecol. Appl., 2005, 15, 1487-1494

[11] Boulet M., Gibbs H.L., Hobson K.A., Integrated analysis of genetic, stable isotope, and banding data reveal migratory connectivity and flyways in the Northern Yellow Warbler (Dendroica petechia; aestiva group), Ornithol. Monogr., 2006, 61, 29-78

[12] Laughlin A.J., Taylor C.M., Bradley D.W., Leclair D., Clark R.C., Dawson R.D., et al., Integrating information from geolocators, weather radar, and citizen science to uncover a key stopover area of an aerial insectivore, Auk, 2013, 130, 230-239

[13] Hobson K.A., Wilgenburg S.L.V., Dunn E.H., Hussell D.J.T., Taylor P.D., Collister D.M., Predicting origins of passerines migrating through Canadian migration monitoring stations using stablehydrogen isotope analyses of feathers: a new tool for bird conservation, Avian Conserv. Ecol., 2015, 10, art3

[14] Wassenaar L.I., Hobson K.A., A stable-isotope approach to delineate geographical catchment areas of avian migration monitoring stations in North America, Environmental Science and Technology, 2001, 35, 1845-1850

[15] Dunn E.H., Hobson K.A., Wassenaar L.I., Hussel D.J.T., Allen M., Identification of summer origins of songbirds migrating through southern Canada in autumn, Avian Conserv. Ecol., 2006, 1, 1-22

[16] Norris D.R., Marra P.P., Seasonal interactions, habitat quality, and population dynamics in migratory birds, The Condor, 2007, 109, 535-547

[17] Runge M., Marra P.P. Modeling seasonal interactions in the population dynamics of migratory birds, In: Greenberg R., Marra P.P. (Eds.), Birds of two worlds: The ecology and evolution of temperate-tropical migration, Baltimore Maryland, Johns Hopkins University Press, 2005, 375-389

[18] Paxton K.L., Van Riper C., III, Theimer T.C., Paxton E.H., Spatial and temportal migration patterns of Wilson's warbler (Wilsonia pusila) in the southwest as revealed by stable isotopes, Auk, 2007, 124, 162-175

[19] Bowen G.J., Wassenaar L.I., Hobson K.A., Global application of stable hydrogen and oxygen isotopes to wildlife forensics, Oecologia, 2005, 143, 337-348

[20] Mazerolle D.F., Hobson K.A., Estimating origins of shortdistance migrant songbirds in North America: Contrasting inferences from hydrogen isotope measurements of feathers, claws, and blood, Condor, 2005, 107, 280-288

[21] Wilgenburg S.L.V., Hobson K.A., Combining stable-isotope (סD) and band recovery data to improve probabilistic assignment of migratory birds to origin, Ecol. Appl., 2011, 21, 1340-1351

[22] Kelly J.F., Atudorei V., Sharp Z.D., Finch D.M., Insights into Wilson's Warbler migration from analyses of hydrogen stableisotope ratios, Oecologia, 2002, 130, 216-221

[23] Clegg S.M., Kelly J.F., Kimura M., Smith T.B., Combining genetic markers and stable isotopes to reveal population connectivity and migration patterns in a Neotropical migrant, Wilson's warbler (Wilsonia pusilla), Mol. Ecol., 2003, 12, 819-830

[24] Kelly J.F., Stable isotope evidence links breeding geography and migration timing in wood warblers (Parulidae), Auk, 2006 $123,431-437$

[25] Conklin J.R., Battley P.F., Potter M.A., Ruthrauff D.R., Geographic variation in morphology of Alaska-breeding Bar-tailed Godwits (Limosa lapponica) is not maintained on their nonbreeding grounds in New Zealand, The Auk, 2011, 128, 363-373

[26] Rushing C.S., Ryder T.B., Saracco J.F., Marra P.P., Assessing migratory connectivity for a long-distance migratory bird using multiple intrinsic markers, Ecol. Appl., 2014, 24, 445-456

[27] Smetzer J.R., King D.I., Prolonged stopover and consequences of migratory strategy on local-scale movements within a regional songbird staging area, Auk, 2018, 135, 547-560

[28] Smetzer J.R., King D.I., Taylor P.D., Fall migratory departure decisions and routes of blackpoll warblers Setophaga striata and red-eyed vireos Vireo olivaceus at a coastal barrier in the Gulf of Maine, J. Avian Biol., 2017, 48, 1451-1461

[29] DeLuca W.V., Woodworth B.K., Rimmer C.C., Marra P.P., Taylor P.D., McFarland K.P., et al., Transoceanic migration by a $12 \mathrm{~g}$ songbird, Biol. Lett., 2015, 11, 1-4

[30] Leppold A.J., Behavioral ecology of landbird migrants in a complex and changing flyway system: The Gulf of Maine, The University of Maine, Orono, 2016 
[31] Leppold A.J., Mulvihill R.S. The Boreal Landbird Component of Migrant Bird Communities in Eastern North America, In: Wells J. (Eds.), Boreal birds of North America, Berkeley California, University of California Press, 2011, 73-83

[32] DeSante D.F., Kaschube D.R., The Monitoring Avian Productivity and Survivorship (MAPS) program 2004, 2005, and 2006 report, Bird Populations, 2009, 9, 860-169

[33] Pyle P., Identification guide to North American Birds. Part I: Columbidae to Ploceidae, Bolinas, CA, Slate Creek Press, 1997

[34] DeLuca W.V., Hunt P.D., Eliason B.C., Blackpoll warbler (Setophaga striata), Birds North Am. Online, 2013

[35] Morris S.R., Covino K.M., Jacobs J.D., Taylor P.D., Fall migratory patterns of the Blackpoll Warbler at a continental scale, Auk, 2015, 133, 41-51

[36] Wassenaar L.I., Hobson K.A., Comparative equilibration and online technique for determination of non-exchangeable hydrogen of keratins for use in animal migration studies, Isotopes Environ. Health Stud., 2003, 39, 211-217

[37] Bowen G.J., Isoscapes: Spatial pattern in isotopic biogeochemistry, Annu. Rev. Earth Planet Sci., 2010, 38, 161-187

[38] Hobson K.A., Wilgenburg S.L.V., Wassenaar L.I., Larson K., Linking hydrogen $(\delta 2 \mathrm{H})$ isotopes in feathers and precipitation: Sources of variance and consequences for assignment to isoscapes, PLoS One, 2012, 7, 1-9

[39] Chabot A.A., Hobson K.A., Van Wilgenburg S.L., McQuat G.J., Lougheed S.C., Advances in linking wintering migrant birds to their breeding-ground origins using combined analyses of genetic and stable isotope markers, PLoS One, 2012, 7, 1-9

[40] Hobson K.A., Wunder M.B., Van Wilgenburg S.L., Clark R.G., Wassenaar L.I., A Method for Investigating Population Declines of Migratory Birds Using Stable Isotopes: Origins of Harvested Lesser Scaup in North America, PLoS One, 2009, 4, 1-10

[41] R Core Team, R: A language and environment for statistical computing. R Foundation for Statistical Computing, Vienna, Austria, 2020

[42] Becker R.A., Wilks A.R., Minka T.P., Deckmyn A., maps: Draw Geographical Maps, R package version 3.3.0, 2018

[43] Bivand R.S., Lewin-Koh N., maptools: tools for reading and handling spatial objects. $R$ package, ver. 0.8-362015

[44] Hijmans R.J., raster: Geographic Data Analysis and Modeling, R package version 3.1-5, 2020

[45] Haché S., Hobson K.A., Villard M.A., Bayne E.M., Assigning birds to geographic origin using feather hydrogen isotope ratios $(\delta 2 \mathrm{H})$ : importance of year, age, and habitat, Can. J. Zool., 2012, $90,722-728$
[46] Holberton R.L., Van Wilgenburg S.L., Leppold A.J., Hobson K.A., Isotopic ( $\delta 2 \mathrm{Hf}$ ) evidence of "loop migration" and use of the Gulf of Maine Flyway by both western and eastern breeding populations of Blackpoll Warblers, J. Field Ornithol., 2015, 86, 213-228

[47] Lloyd-Evans T.L., Atwood J.L., 32 years of changes in passerine numbers during spring and fall migrations in coastal Massachusetts, Wilson Bulletin, 2004, 116, 1-16

[48] Sauer J.R., Niven H.E., Hines D.H., Ziolkowski D.H., Jr., Pardieck K.L., Fallown H.E., et al., The North American Breeding Bird Survey, Results and Analysis 1966 - 2015, Version 2.07.2017 USGS Patuxent Wildlife Research Center, Laurel, MD, 2017

[49] Cimprich D.A., Moore F.R., Guilfoyle M.P., Red-eyed vireo (Vireo olivaceus), Birds North Am. Online, 2000

[50] Warnock N., Stopping vs. staging: The difference between a hop and a jump, J. Avian Biol., 2010, 41, 621-626

[51] Rosenberg K.V., Kennedy J.A., Dettmers R., Ford R.P., Reynolds D., Alexander J.D., et al., Partners in flight landbird conservation plan: 2016 revision for Canada and continental United States. Partners in Flight Science Committee, 2016

[52] Hansen M.C., Potapov P.V., Moore R., Hancher M., Turbubanova S.A., Tyukavina A., et al., High-resolution global maps of 21st-century forest cover change, Science, 2013, 342, 850-853

[53] Kirchman J.J., Ralston J., Gifford N.a., Stable isotope analysis of fall migration stopover by six passerine species in an inland pitch pine-scrub oak barren, The Wilson Journal of Ornithology, 2011, 123, 548-556

[54] Rappole J.H., The avian migrant, New York, NY, Columbia University Press, 2013

[55] La Sorte F.A., Hochachka W.M., Farnsworth A., Sheldon D., Fink D., Geevarghese J., et al., Migration timing and its determinants for nocturnal migratory birds during autumn migration, J. Anim. Ecol., 2015, 84, 1202-1212

[56] Smith R.B., Meehan T.D., Wolf B.O., Assessing migration patterns of sharp-shinned hawks, J. Avian Biol., 2003, 34, 387-392

[57] Pienkowski A.M.W., Evans P.R., Townshend D.J., Leap-Frog and Other Migration Patterns of Waders: A Critique of the Alerstam and Högstedt Hypothesis, and Some Alternatives, Ornis Scandinavica, 1985, 16, 61-70 